\title{
Relationships Between Work, Organisational Re-engineering and Information Systems
}

\author{
Patsy Segall
}

Union Research Centre on
Organisation and Technology

171 La Trobe Street

Melbourne Australia 3000

zpatsy@minyos.its.rmit.edu.au
Andrew Clement

Faculty of Information

Studies

University of Toronto

140 George Street

Toronto Canada M5S 1A1

clement@fis.utoronto.ca
Toni Robertson

\author{
School of Information \\ Systems \\ University of New South \\ Wales
}

Sydney Australia 2052

t.robertson@unsw.edu.au

\begin{abstract}
This workshop is sponsored by IFIP WG9.1 (Computers and Work), and the Union Research Centre on Organisation and Technology (URCOT). Increasingly organisations are under pressure to change their work practices and organisational structures. Typically these changes are supported by information and communication technologies that have major impacts on jobs, the workplace itself, and employment generally. Yet HCI research and practice have tended to focus on the interface between the individual user and the computer. This focus has excluded the relationships between the technology, the people who use it, the organisational environment and the work the technology is intended to support. The goal of the workshop is to clarify both the dynamics between organisational restructure and technological systems, as well as their implications for the work that is required to use the systems, how this is performed and under what conditions.
\end{abstract}

KEYWORDS Business process re-engineering, $\mathrm{HCI}$ in organisations, industrial democracy, management issues, user participation

\section{PARTICIPANTS' PERSPECTIVES}

Workshop participants will bring a range of perspectives to the issues under examination:

- experience in a particular kind of workplace, for example a teleservice centre;

- industry perspectives, for example the finance sector;
- specific areas under development for example electronic commerce;

- experience with a particular industrial agreement or dispute;

- analysis of relevant labour market and employment trends;

- case studies of organisational restructure and technological innovation. 


\section{ISSUES IN ORGANISATIONAL CHANGE}

There are pressures on organisations to restructure. Different types of organisational change have different implications and impacts. Examples include:

- business process re-engineering;

- multi-functional client-based teams;

- elimination of functions;

- downsizing;

- contracting of work, internally, externally;

- dispersal of work in space and time.

\subsection{The Role of IT in Organisational Restructure}

Requirements gathering for information systems involves multiple stakeholders, and is of great complexity.

The computer interface and systems can support intelligent, autonomous work (both individual and team) or enable 'plugging in' of operators to limited data entry or enquiry roles.

For systems developers there are specific issues:

- relationships with internal, cxternal clients;

- responsibility for impact assessment;

- responsibility for user participation.

\subsection{Employment and Quality of Work}

For workers and their unions many issues arise:

- new kinds of work and employment relationships;

- hours and location of work;

- value of local knowledge and tailored customer service v. homogeneous service;

- if the technology is easy to use and requires little training, work can be moved off-shore relatively cheaply;

- worker participation in decision making and systems development;

- what should unions aim for in industrial agreements?

- relationships between unions in different countrics.

\section{ORGANISATION OF THE WORKSHOP}

Participants will provide position papers for advance distribution. Formal group discussion of the papers will take place on 14 July, followed by optional participation in an additional half day's discussion to plan publication of material incorporating key aspects of papers and discussion. 